\title{
Single-cell screening of photosynthetic growth and lactate production by cyanobacteria
}

\author{
Petter Hammar ${ }^{1,2}$, S. Andreas Angermayr ${ }^{3,4}$, Staffan L. Sjostrom ${ }^{1,2}$, Josefin van der Meer ${ }^{1}$, Klaas J. Hellingwerf ${ }^{3}$, \\ Elton P. Hudson ${ }^{1 *}$ and Haakan N. Joensson ${ }^{1,2^{*}}$
}

\begin{abstract}
Background: Photosynthetic cyanobacteria are attractive for a range of biotechnological applications including biofuel production. However, due to slow growth, screening of mutant libraries using microtiter plates is not feasible.

Results: We present a method for high-throughput, single-cell analysis and sorting of genetically engineered L-lactate-producing strains of Synechocystis sp. PCC6803. A microfluidic device is used to encapsulate single cells in picoliter droplets, assay the droplets for L-lactate production, and sort strains with high productivity. We demonstrate the separation of low- and high-producing reference strains, as well as enrichment of a more productive L-lactatesynthesizing population after UV-induced mutagenesis. The droplet platform also revealed population heterogeneity in photosynthetic growth and lactate production, as well as the presence of metabolically stalled cells.
\end{abstract}

Conclusions: The workflow will facilitate metabolic engineering and directed evolution studies and will be useful in studies of cyanobacteria biochemistry and physiology.

Keywords: Cyanobacteria, Single cell, Droplet microfluidics, High-throughput screening, Lactate dehydrogenase

\section{Background}

Cyanobacteria are model organisms for the study of biological light harvesting [1], photosynthesis [2], and circadian gene regulation [3]. Additionally, their minimal nutrient requirements and an expanding genetic toolbox have made cyanobacteria attractive for a range of biotechnological applications, such as hosts for next-generation biofuel $[4,5]$ and fine chemical production [6].

Microfluidic droplet emulsion technology $[7,8]$ is emerging as a powerful facilitator for cellular and metabolic engineering, as various devices enable precise single-cell compartmentalization [9], culturing [10], phenotyping [11], and sorting [12]. Recent works have demonstrated the assay and enrichment of microbial and mammalian clones based on substrate consumption [11], secreted proteins [13, 14], and metabolites [11]. Additionally, single-cell technology allows study of population

\footnotetext{
*Correspondence: huds@kth.se; hakan.jonsson@scilifelab.se

1 science for Life Laboratory, Division of Proteomics

and Nanobiotechnology, KTH Royal Institute of Technology, Stockholm,

Sweden

Full list of author information is available at the end of the article
}

heterogeneities in metabolism and can thus potentially uncover rare metabolic states not visible in bulk assays [15].

Here we report a droplet microfluidic workflow which combines several microfluidic devices to encapsulate, assay, and sort L-lactate-producing strains of the cyanobacterium Synechocystis sp. PCC6803 (Synechocystis). A UV-mutagenized population was sorted and a clear enrichment of high-producing strains was observed. We also used the droplet platform to measure population heterogeneities in Synechocystis growth and L-lactate production and their dependence on a circadian darklight cycle.

\section{Results and discussion}

The workflow begins with encapsulation of single Synechocystis cells in picoliter droplets $(10 \mathrm{pL})$ containing growth medium (Fig. 1a). The resulting droplet emulsion is incubated under light, where L-lactate (lactate) is produced and secreted within each droplet. Droplets are loaded onto a second device, where a picoinjector [16] adds a lactate assay enzyme solution $(10 \mathrm{pL})$ into each 


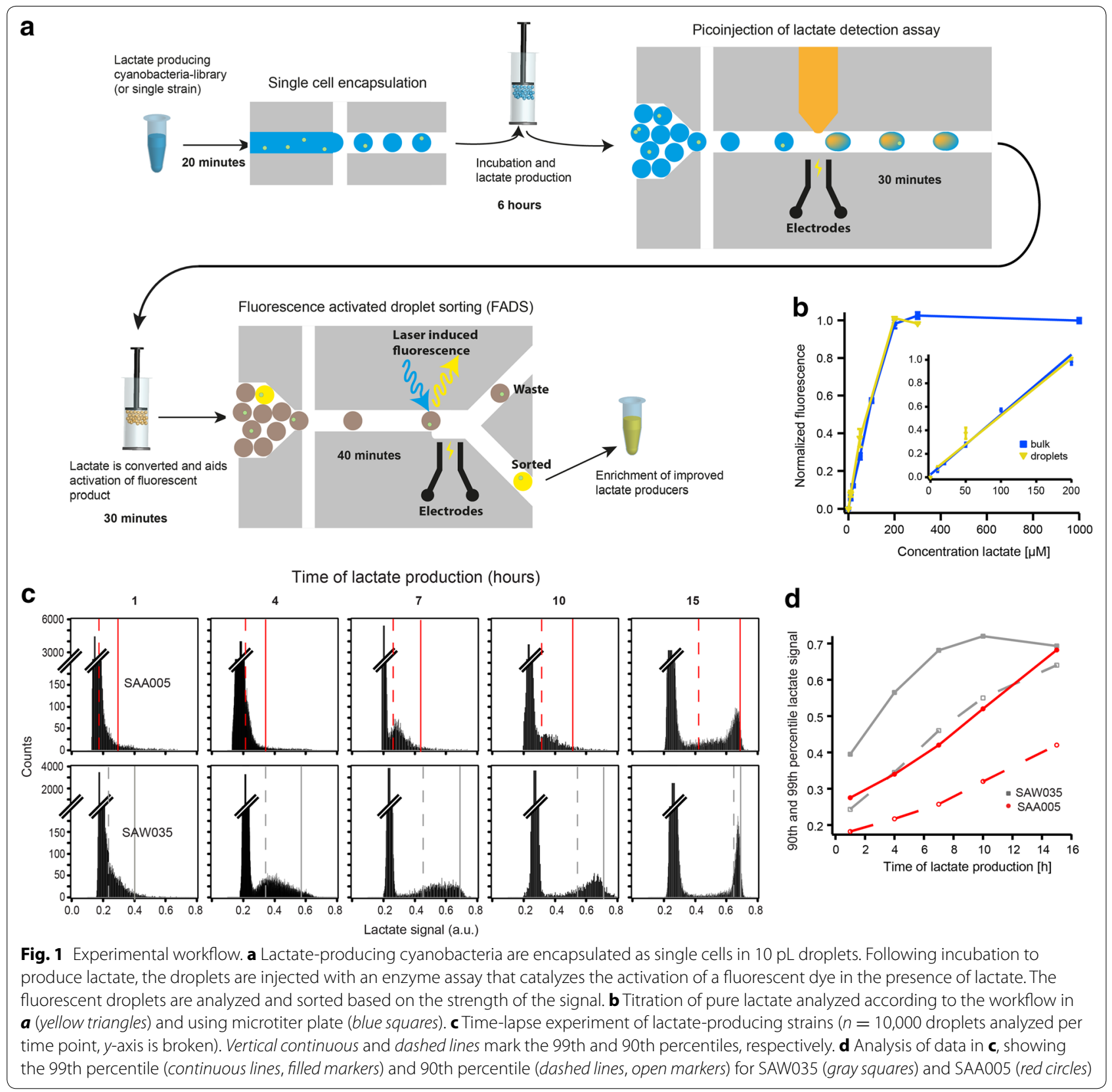

droplet via electrocoalescence, resulting in a fluorescence response. Picoinjection is preferable to co-encapsulation of cells with assay solution because it decouples photoautotrophic lactate production $(6 \mathrm{~h})$ from the lactate assay (30 $\mathrm{min}$ ), thus allowing the use of assay reagents that may be transported out of droplets on a longer timescale or that are light sensitive. After picoinjection, droplets are screened $\left(10^{3}\right.$ droplets $\left./ \mathrm{s}\right)$ and sorted $\left(10^{2}-10^{3}\right.$ droplets $\left./ \mathrm{s}\right)$ in a third device using fluorescence-activated droplet sorting (FADS) [17]. The sorted emulsion is spread on agar plates for colony formation and counting after incubation in light. Calibration assays using pure lactate (no cells) showed a linear response from 10 to $200 \mu \mathrm{M}$ lactate, which is comparable to a $50 \mu \mathrm{L}$ microtiter plate assay using the same reagents (Fig. 1b; Additional file 1: Fig. S1). Fluorescence distributions of calibration samples (no cells) provided a measure of total technical variation of the encapsulation, picoinjection, and enzymatic assay steps (Additional file 1: Fig. S2a-c). Details are available in the "Methods" section and the additional file 1.

We sought to determine the incubation time that maximizes assay resolution between lactate-producing 
Synechocystis strains. Two engineered Synechocystis strains, SAA005 and SAW035, were selected as low and high lactate producers, respectively $[18,19]$. In microtiter plates, SAW035 has a $5.5 \pm 1.9$-fold (mean \pm SEM, $n=3$ ) higher productivity than SAA005 (Additional file 1: Fig. S3a). We incubated SAA005 and SAW035 in droplets and assayed them for lactate production at different time points. For SAW035, the droplet lactate content was within the linear dynamic range of the assay at $1-10 \mathrm{~h}$ of incubation (4-15 h for SAA005) (Fig. 1c). The differences were shown at the 99th and 90th percentiles for all time points (Fig. 1d). The best resolution was at $4-7 \mathrm{~h}$ incubation time, where the lactate titer for SAW035 was $4.3 \pm 1.4$-fold (mean $\pm \operatorname{SEM}, n=3$ ) higher than for SAA005 (Additional file 1: Fig. S3a), similar to values obtained in a microtiter plate at the same experimental conditions. A subpopulation of cells from each strain did not produce lactate (see, e.g., Fig 1c). This fraction was consistently higher for SAW035 $(27.3 \pm 1.9 \%)$ than for SAA005 $(15.9 \pm 2.8 \%)$ (mean \pm SEM, $n=3$ and $n=5$, respectively) (Additional file 1: Data and Notes).

The droplet platform also allows comparison of growth rates between different clones or strains [20, 21]. To estimate doubling times, we followed cell proliferation from single cells within droplets for both SAA005 and SAW035 (Fig. 2a). The average doubling time of SAA005 in the droplets was approximately $12 \mathrm{~h}$, comparable to batch culture at similar $\mathrm{pCO}_{2}$ and light intensities [18]. The doubling time of SAW035 was longer, as expected. Under optimal conditions, this strain diverts up to $18 \%$ of fixed $\mathrm{CO}_{2}$ to lactate $(<1 \%$ for SAA005) [19]. For both strains, we observed a subpopulation (10-30 \%) that did not divide. We hypothesized that this subpopulation is the non-producing subpopulation observed in lactate assays. We confirmed this by simultaneously monitoring cell division and lactate production in droplets (Additional file 1: Fig. S4a-c). Non-dividing cells did not produce lactate, though a majority of cells were viable at the time of droplet encapsulation as determined by oxonol staining and during droplet incubation as determined by cellular autofluorescence (Additional file 1: Fig. S4d, e). These cells are therefore metabolically stalled on the time scale of this experiment ( $48 \mathrm{~h}$ ).

The observed widths of the distributions of lactate concentration of Synechocystis are influenced by technical but mostly biological variability (Additional file 1 :

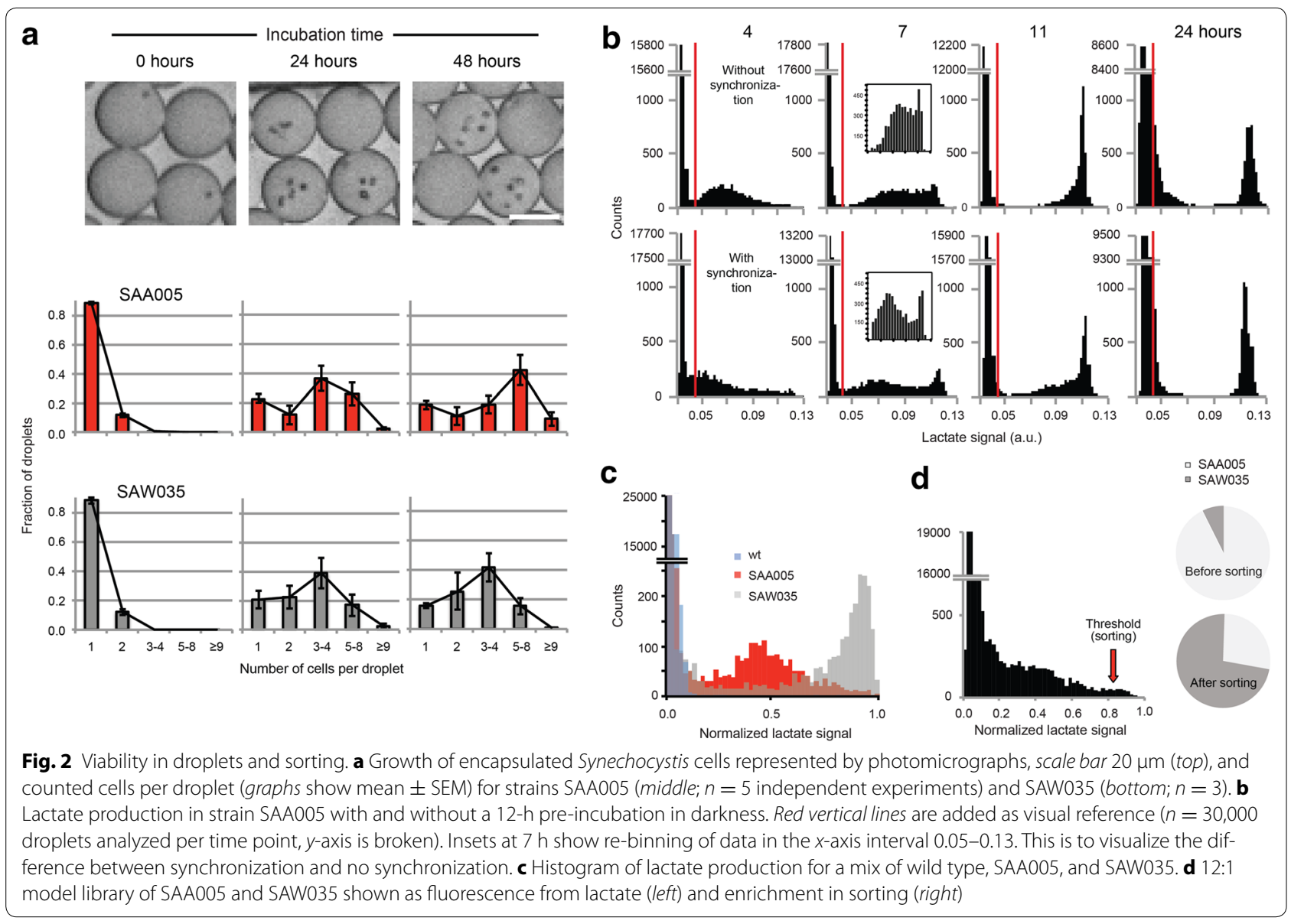


Fig. S2c-e) and were similar for SAA005 and SAW035. Biological heterogeneity could arise from cells being in different growth phases at the time of encapsulation. Different cells will also be in different states of the cell cycle, and a cell that is close to dividing will have almost double the size and more enzymes present compared to a cell that has just divided. High chromosomal copy number [22, 23], growth-phase-dependent DNA replication, and the apparently random chromosome partitioning at division [24, 25] can further add to the heterogeneity of Synechocystis gene expression. However, reduced heterogeneity would increase assay resolution. We attempted to reduce heterogeneity in lactate production of SAA005 by synchronizing gene expression and metabolism with circadian light-dark entrainment [26]. A 12-h dark period was introduced just prior to encapsulation and lactate production. We observed that cells subjected to darkness had a delayed onset of both lactate production and division, but did not exhibit narrower distributions of lactate production compared to those that were treated with continuous light (Fig. 2b; Additional file 1: Fig. S5, Data and Notes).

We next used the droplet platform to assay and sort mixtures of the lactate-producing strains. To estimate enrichment potential, a 1:1:1 mixture of wild-type Synechocystis, SAA005, and SAW035 was assayed. Each strain was barcoded with a known concentration of the dye fluorescein to allow identification (Fig. 2c). After incubation, wild-type droplets did not show detectable lactate levels, indicating no or negligible production. This also suggests that there is no substantial leakage of lactate in between droplets on this time scale. The barcode revealed overlap of SAA005 and SAW035 lactate distributions; a $0.5 \%$ gating threshold contained $95 \%$ of the high-producing SAW035 and $5 \%$ SAA005 (Additional file1: Fig. S3b-d). Perfectly efficient sorting using the $0.5 \%$ gate would thus be expected to enrich the SAW035 strain 38-fold (Additional file 1: Data and Notes). We created a 1:12 mixture of SAW035 and SAA005 and then sorted 5000 cells using the $0.5 \%$ gating threshold and plated them (details in the "Methods" section; Additional file 1: Table S1). SAW035 was enriched 32 -fold as quantified by colony counting (Fig. 2d). This enrichment is comparable to the expected outcome for these two strains, as estimated from the barcode experiment. The theoretically maximal enrichment for non-overlapping populations is 77-fold [17] (Additional file 1: Data and Notes). Three colonies were picked from the plate, and cultures derived thereof were confirmed to produce lactate as expected for the respective strains (Additional file 1: Data and Notes). Total assay time was approximately $8 \mathrm{~h}$; total reagents per single cell were $10 \mathrm{pL}$ each of cell medium and enzyme assay, i.e., $10^{7}$-fold lower than for a corresponding single clone in a $100 \mu \mathrm{L}$ reaction [27].

Finally, a UV-mutagenized population (estimated $4 \times 10^{5}$ members) was created by UV irradiation of the lactate-producing strain SAA023 [18]. The UV irradiation was such that $90-99 \%$ of cells were killed. The UV-irradiated population had a lower average lactate production than the parent strain SAA023 (Fig. 3a). This indicates that UV exposure triggers many harmful mutations that affect growth and lactate production of the cells. The mixture was screened and sorted using a similar procedure as above. A $3 \%$ gating threshold was used, and the sorted fraction was recovered on an agar plate which resulted in $>10,000$ colonies (out of estimated 20-40,000 sorted). An aliquot of the non-sorted library emulsion was plated in the same way and used as a reference sample. The sorting significantly enriched high lactate producers of the UV-mutagenized population (Fig. 3a). The difference in lactate production for the non-sorted and sorted population was also seen when screened in droplets (Fig. 3b).

\section{Conclusions}

We have developed an assay for single-cell screening of lactate production from the cyanobacterium Synechocystis, where droplet encapsulation allows us to couple genotype to production phenotype. We envision the droplet microfluidics platform as a powerful tool with many applications in applied and basic research. Enzymatic, fluorescence-based assays for a range of secreted metabolites have been devised [11]. Simultaneous measurement of productivity and growth adds a new dimension to strain selection from libraries. Furthermore, droplet microfluidics modules are amenable to automation, such that all steps of a directed evolution program could be integrated on a single device and automated; we observed clonal expansion in droplets over several days and emulsion breaking did not harm cells. Such a workflow would eliminate time-consuming plating and colony formation. In particular, for cyanobacteria, droplets can be arranged in monolayers or mixed, ensuring uniform light intensity during incubations.

\section{Methods}

\section{Strain information and growth conditions}

The cyanobacterial wild-type strain used in this study is the glucose-tolerant derivative of Synechocystis sp. PCC6803 (kindly provided by Devaki Bhaya, Stanford, USA). Heterologous insertions were made for the construction of the three lactate-producing strains employed here. Briefly, for the low-producing strain, SAA005, the native L-ldh gene of Lactococcus lactis ssp. cremoris ( $L$. lactis) and a kanamycin resistance cassette were inserted 

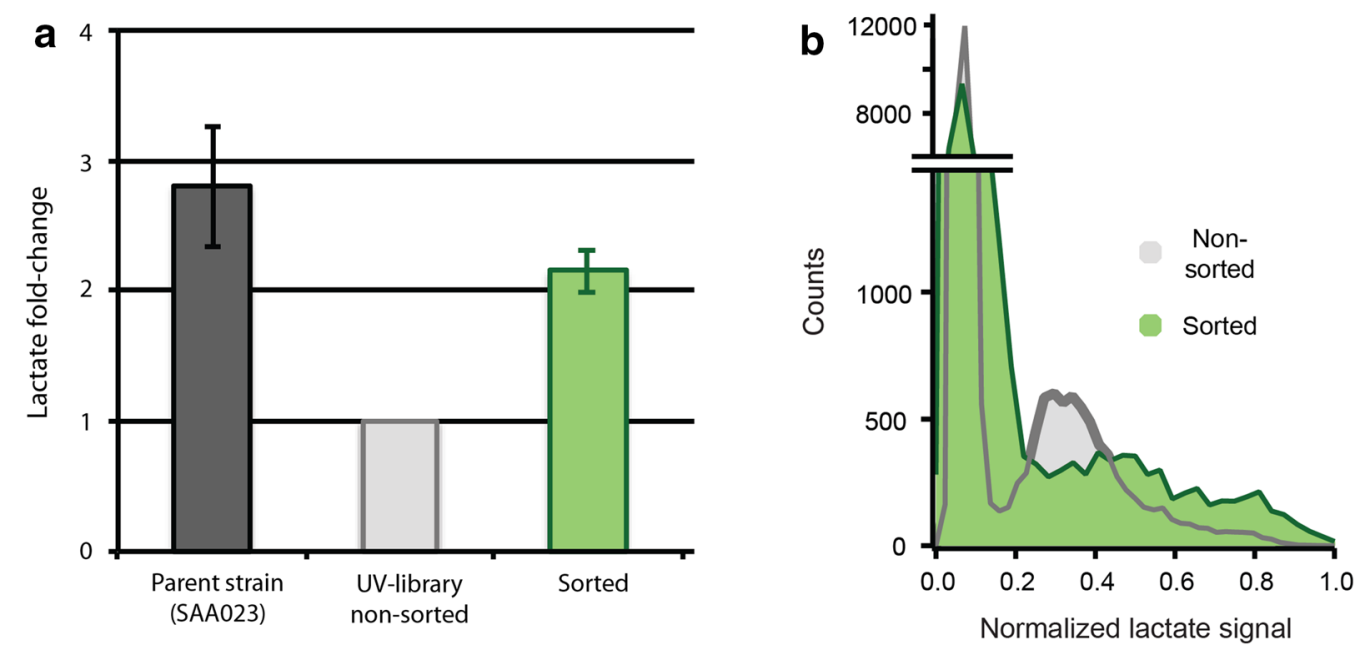

Fig. 3 Sorting a large UV mutagenesis library. a Bulk lactate production measured in microtiter plate. Parent strain SAA023 is compared to the non-sorted UV-generated mixture and the droplet-sorted fraction $(n=5)$. Data represents technical replicates (the same sorted fraction screened for lactate at different days after sorting). Lactate production is normalized to that of the non-sorted population in each experiment and is shown as average \pm SEM $(n=5)$. b Lactate production in droplets of the non-sorted (gray) and the sorted fraction (green); $n=30,000$ droplets analyzed per sample, $y$-axis is broken. A clear enrichment of high-producing strains is observed

downstream of the $p s b A 2$ open reading frame in the Synechocystis genome [18]. For the medium-producing strain, SAA023, a codon-optimized version of the L. lactis ldh gene was flanked by the promoter Ptrc and a transcriptional terminator fused to a kanamycin resistance cassette and inserted into the genome of Synechocystis targeting slr0168 [18]. For the high-producing strain, SAW035, the codon-optimized ldh gene of L. lactis was fused to Ptrc and cloned into the pDF-plasmid, and transformed into Synechocystis by bacterial conjugation as reported in [19]. Cells were cultivated in BG-11 supplemented with $50 \mathrm{mM} \mathrm{NaHCO} 3(\mathrm{pH}$ 8) (BG-11-NaHCO 3 ) and $20 \mu \mathrm{g} / \mathrm{ml}$ kanamycin (SAA005 and SAA023) or $25 \mu \mathrm{g} / \mathrm{ml}$ spectinomycin (SAW035) in flasks shaking at $180 \mathrm{rpm}$ at $30{ }^{\circ} \mathrm{C}$ (CLF Plant Climatics) and illuminated with white light $\left(30-35 \mu \mathrm{E} / \mathrm{m}^{2} / \mathrm{s}\right)$. Solid medium plates were prepared by adding $1.5 \%(\mathrm{w} / \mathrm{v})$ agar, $10 \mathrm{mM}$ TES$\mathrm{KOH}(\mathrm{pH} 8)$ and $0.3 \%(\mathrm{w} / \mathrm{v})$ sodium thiosulfate to BG-11, and antibiotics were added if appropriate. During growth of the SAA023-derived UV-mutagenized cells, kanamycin was always present and no $\mathrm{NaHCO}_{3}$ was added.

\section{Microfluidic chip manufacturing}

Figure 1a illustrates the overall experimental setup. Microfluidic chips were designed and manufactured in polydimethylsiloxane (PDMS) (Dow Corning) as described in [14] for the sorting chip, and in [28] for the generation and picoinjector chips with the following modifications: the droplet generation chip had a nozzle width of $25 \mu \mathrm{m}$; the picoinjector chip had reinjection and picoinjection nozzle widths of 22 and $16 \mu \mathrm{m}$, respectively, and a channel depth of $25 \mu \mathrm{m}$. The devices were bonded on glass slides using oxygen plasma, the electrodes were fabricated (when applicable) by injecting low-melting point solder (Indium Corp.), and the channels of the chip were surface treated with Aquapel (PPG Industries) followed by pressurized air.

\section{Droplet generation}

Synechocystis cultures were started from plate and incubated for 3-4 days in batch. 12-24 h before harvesting, the cultures were diluted to assure growing cells with an $\mathrm{OD}_{730}$ of $0.4-0.6$ at the time of harvest. Upon harvesting, the cells were washed twice in BG-11 medium and resuspended in $\mathrm{BG}-11-\mathrm{NaHCO}_{3}$ to $\mathrm{OD}_{730}=0.2-0.3$. Except for in the sorting experiments, prior to droplet encapsulation the separate strains (or pure lactate samples) were mixed with different concentrations of fluorescein (Sigma-Aldrich) (0 for wild type, 2 for SAA005, and $10 \mu \mathrm{M}$ for SAW035) to allow discrimination according to the fluorescence signal (laser excitation at $491 \mathrm{~nm}$, emission filter 525/20 nm) and kept in 1-mL plastic syringes (BD plastic). A mix of HFE-7500 oil and $1 \%(w / w)$ EA surfactant droplet stabilizer (RainDance Technologies) was loaded into a Gastight 5 -mL glass syringe (Hamilton). Cells were encapsulated in $10 \mathrm{pL}$ droplets essentially as reported earlier [14] using a flow rate of $400 \mu \mathrm{L} / \mathrm{h}$ for the aqueous solution and $2000 \mu \mathrm{L} / \mathrm{h}$ for the oil. The emulsion was collected in a 1-mL plastic syringe at a withdrawal flow rate of $2000 \mu \mathrm{L} / \mathrm{h}$. The syringes were connected to the chip by polyether ether ketone tubing, and flow rates 
were controlled by neMESYS syringe pumps (Cetoni $\mathrm{GmbH})$. The initial cell concentration used gives on average 0.2 cells per droplet and about ten times more droplets with one compared to two cells at the time of droplet generation. 1 cell per $10 \mathrm{pL}$ droplet corresponds to $\mathrm{OD}_{730}=1$ (Additional file 1: Data and Notes). The different strains or lactate samples were encapsulated sequentially and collected in the same syringe, or mixed prior to washing and encapsulated within 30 min (time between washing and last droplet encapsulated, resembling a library situation). The emulsions were kept in syringes, placed under light $\left(30-35 \mu \mathrm{E} / \mathrm{m}^{2} / \mathrm{s}\right)$, and incubated for lactate production as indicated for each experiment. For the lactate titration experiment (Fig. 1b), no incubation was needed.

\section{Lactate detection assay}

Following incubation, the picoinjector chip [28] was used to supplement the droplets with a L-lactate assay mixture (Cayman Chemical Company). In brief, $1 \times$ solutions of the kit reagents were prepared according to the manufacturer's instruction and mixed as 1 volume cofactor mixture, 1 volume fluorescent substrate, 2 volumes of enzyme mixture, and 1 volume bovine serum albumin (BSA, $1 \% \mathrm{w} / \mathrm{v}$, not supplied in the kit). BSA was added to slow the leakage of the fluorescent product between droplets. The assay mixture was loaded into a $1-\mathrm{mL}$ plastic syringe. When picoinjecting, the droplet emulsion was injected to the chip at a flow rate of $70 \mu \mathrm{L} / \mathrm{h}$, the oil-surfactant mix separated the droplets (supplied at a flow rate of $500 \mu \mathrm{L} / \mathrm{h}$ ), and the enzyme mix was added at a flow rate of $40 \mu \mathrm{L} / \mathrm{h}$. The droplets and enzyme mix met at a channel junction next to the in-built electrode, and droplets and enzyme mix were fused at a 1:1 volume ratio to form $20 \mathrm{pL}$ droplets when an electrical field was applied (constant applied voltage of $0.6 \mathrm{kV}$ at $30 \mathrm{kHz}$ ). The processed droplets were collected in a 1-mL plastic syringe at a withdrawal flow rate of $550 \mu \mathrm{L} / \mathrm{h}$, and incubated (in darkness) for 30-40 min after collection was finished. In the enzymatic reaction, lactate dehydrogenase catalyzes the oxidation of L-lactate into pyruvate, and $\mathrm{NAD}^{+}$is reduced to $\mathrm{NADH}+\mathrm{H}^{+}$. In the subsequent step, $\mathrm{NADH}$ reacts with and activates the fluorescent substrate.

\section{Detection and sorting}

Droplets were injected into the sorting chip at a flow rate of $30 \mu \mathrm{L} / \mathrm{h}$ and were separated by the oil-surfactant mix supplied at a flow rate of $500 \mu \mathrm{L} / \mathrm{h}$. The droplets passed a $491 \mathrm{~nm}$ laser beam (Cobolt Calypso CW $<100 \mathrm{~mW}$ ), which was focused through a $10 \times$ objective lens onto a point close to the built-in electrode. Fluorescence was detected using two separate emission filters $(525 / 20 \mathrm{~nm}$ for fluorescein and 593/20 nm for the lactate fluorescent substrate) and photomultiplier tubes (PMTs) (Hamatsu). The main channel of the chip splits into two just downstream of the excitation/electrode point (Fig. 1a, bottom), one channel leading to a waste vial and one leading to a collection port connected to a 1-mL plastic syringe, set to a withdrawal flow rate of $165 \mu \mathrm{L} / \mathrm{h}$. The PMTs were connected to a Field Programmable Gate Array (National Instruments) programmed to activate a voltage pulse when the fluorescent signal detected exceeded a gating intensity. The voltage pulse was then amplified in a highvoltage amplifier (TREK Inc.) connecting to the built-in electrodes. The amplified voltage pulse $(0.8-1 \mathrm{kV}, 800 \mu \mathrm{s}$, $30 \mathrm{kHz}$ ) routed the droplet to the collection syringe, while in the absence of a pulse droplets would follow the default route to the waste.

\section{Strain verification and enrichment quantification}

After sorting, the collected emulsion was mixed with emulsion breaker $(1 \mathrm{H}, 1 \mathrm{H}, 2 \mathrm{H}, 2 \mathrm{H}$-perfluoro-1-octanol, Sigma-Aldrich) and medium to separate the cells from the oil, and spread on BG-11 plates. Equal aliquots were spread on plates containing kanamycin or spectinomycin. The two strains strictly grow on their selective condition (SAA005 has only kanamycin resistance and SAW035 has only streptomycin/spectinomycin resistance). Following 10 days of incubation, colonies were counted and the enrichment quantified (Additional file 1: Data and Notes).

\section{Library construction and sorting}

The mixture of UV-mutagenized SAA023 cells was generated as follows [29]. UV irradiation of the SAA023 strain was done in an Amersham Bioscience UVC 500 DNA cross-linker with $4 \times 8$ W UV-B bulbs (emission $254 \mathrm{~nm}$ ). Three sub-libraries of different UV irradiation were created: 60,75 , and $100 \mathrm{~J} / \mathrm{m}^{2}$. For each sub-library, $250 \mu \mathrm{L}$ of SAA023 culture at $\mathrm{OD}_{730}=2$ was aliquoted into a 40-mm petri dish and exposed to the UV dosage. To prevent photolyase-mediated DNA repair, cells were kept in the dark until plated $(250 \mu \mathrm{L})$ on BG-11 agar plates containing kanamycin. The plates were then covered with Asmetec SFG10 $520 \mathrm{~nm}$ filter foil and placed in an incubator at $30 \mu \mathrm{E} / \mathrm{m}^{2} / \mathrm{s}$ white light, $30{ }^{\circ} \mathrm{C}$, and $1 \%$ $\mathrm{CO}_{2}$. An estimated $5 \times 10^{3}\left(100 \mathrm{~J} / \mathrm{m}^{2}\right)$ and $5 \times 10^{4}(60$ and $75 \mathrm{~J} / \mathrm{m}^{2}$ ) colonies per plate were recovered after 2 weeks of cultivation for each UV intensity. An untreated sample gave approximately $5 \times 10^{5}$ colonies. Eight replicates of each sample were made, so that the total library size was approximately $4 \times 10^{4}\left(100 \mathrm{~J} / \mathrm{m}^{2}\right)$ and $4 \times 10^{5}(60$ and $75 \mathrm{~J} / \mathrm{m}^{2}$ ). The UV-treated cells were scraped from the plates, resuspended in BG-11 medium containing $7 \% \mathrm{v} / \mathrm{v}$ DMSO, and stored at $-80^{\circ} \mathrm{C}$. 
The three fractions irradiated with increasing intensity $\left(60,75\right.$, and $\left.100 \mathrm{~J} / \mathrm{m}^{2}\right)$ were started from glycerol stocks 1 week prior to the first sorting experiment. Mixing these at equal ratios created our UV library. This mixture was washed and encapsulated in droplets as described above. Picoinjection and droplet sorting was performed following 6-h incubation in light, screening $3 \times 10^{5}$ cells and using a gating threshold of $3 \%$ of all droplets. The sorted fraction was spread on BG-11 agar plates containing kanamycin. An aliquot of the remaining non-sorted emulsion was also plated and used as reference in all subsequent measurements. After 2 weeks of incubation, colonies were scraped from the plates and cultured in liquid medium for another week. Lactate production was measured in microtiter plate and in droplets.

\section{Growth in droplets}

Cells of SAA005 and SAW035 were encapsulated in droplets and collected in separate syringes as described above. Droplets were imaged at generation, or after 24 and $48 \mathrm{~h}$ of incubation and reinjection into a new microfluidic device, using $10 \times$ optical magnification where essentially all cells are observed in the same focal plane, and a Stingray F-033B camera (Allied Vision). Analysis was performed through manual counting of cells in droplets. One limitation in the analysis is to separate nearby cells, and data are therefore presented with binning, assuming full cell cycle events (for example, '5-8 cells' means a single cell has divided three times).

\section{Synchronization experiment}

Growth in droplets and lactate detection was performed as described above; however, samples were covered in aluminium foil and incubated for $12 \mathrm{~h}$ prior to encapsulation in droplets. Analysis was done after 0, 12, 24, and $48 \mathrm{~h}$ of incubation.

\section{Additional file}

Additional file 1. Supplementary information

\section{Abbreviations}

FADS: fluorescence-activated droplet sorting; Lactate: L-lactate; Synechocystis: Synechocystis sp. PCC6803; PDMS: polydimethylsiloxane; PMT: photomultiplier tube.

\section{Authors' contributions}

PH carried out microfluidics experiments and lactate measurements, analyzed microfluidics data, and drafted the manuscript. SAA carried out strain characterization and drafted the manuscript. SLS participated in the microfluidics experiments and helped to draft the manuscript. JVDM constructed the UV-mutagenized library and helped to draft the manuscript. KJH helped to draft the manuscript. EPH participated in the lactate measurements, drafted the manuscript, and coordinated the study. $\mathrm{HJ}$ drafted the manuscript and coordinated the study. All authors read and approved the final manuscript.

\section{Author details}

${ }^{1}$ Science for Life Laboratory, Division of Proteomics and Nanobiotechnology, KTH Royal Institute of Technology, Stockholm, Sweden. ${ }^{2}$ Novo Nordisk Foundation Center for Biosustainability, KTH Royal Institute of Technology, Stockholm, Sweden. ${ }^{3}$ Swammerdam Institute for Life Sciences, University of Amsterdam, Amsterdam, The Netherlands. ${ }^{4}$ Present Address: Institute of Science and Technology (IST) Austria, Klosterneuburg, Austria.

\section{Acknowledgements}

This research was funded in part ( $\mathrm{PH}$ and $\mathrm{HJ}$ ) by the Novo Nordisk Foundation Center for Biosustainability. EPH acknowledges a SciLifeLab Fellowship. SAA and $\mathrm{KJH}$ are supported by the research program of BioSolar Cells, co-financed by the Dutch Ministry of Economic Affairs, Agriculture and Innovation. We would like to acknowledge RainDance Technologies for providing the surfactant used in the experiments.

\section{Competing interests}

The authors declare that they have no competing interests.

Received: 9 September 2015 Accepted: 9 November 2015

Published online: 25 November 2015

\section{References}

1. Croce $\mathrm{R}$, van Amerongen $\mathrm{H}$. Natural strategies for photosynthetic light harvesting. Nat Chem Biol. 2014;10(7):492-501. doi:10.1038/ nchembio.1555.

2. Kramer DM, Evans JR. The importance of energy balance in improving photosynthetic productivity. Plant Physiol. 2011;155(1):70-8. doi:10.1104/ pp.110.166652.

3. Yang Q, Pando BF, Dong G, Golden SS, van Oudenaarden A. Circadian gating of the cell cycle revealed in single cyanobacterial cells. Science. 2010;327(5972):1522-6. doi:10.1126/science.1181759.

4. Atsumi S, Higashide W, Liao JC. Direct photosynthetic recycling of carbon dioxide to isobutyraldehyde. Nat Biotechnol. 2009;27(12):1177-80. doi:10.1038/nbt.1586.

5. Savakis $\mathrm{P}, \mathrm{Hellingwerf} \mathrm{KJ}$. Engineering cyanobacteria for direct biofuel production from CO. Curr Opin Biotechnol. 2014;33C:8-14. doi:10.1016/j. copbio.2014.09.007

6. Ducat DC, Way JC, Silver PA. Engineering cyanobacteria to generate high-value products. Trends Biotechnol. 2011;29(2):95-103. doi:10.1016/j. tibtech.2010.12.003

7. Song $\mathrm{H}$, Chen DL, Ismagilov RF. Reactions in droplets in microfluidic channels. Angew Chem. 2006;45(44):7336-56. doi:10.1002/anie.200601554.

8. Joensson HN, Andersson Svahn H. Droplet microfluidics-a tool for single-cell analysis. Angew Chem. 2012;51(49):12176-92. doi:10.1002/ anie. 201200460

9. Huebner A, Srisa-Art M, Holt D, Abell C, Hollfelder F, deMello AJ, et al. Quantitative detection of protein expression in single cells using droplet microfluidics. Chem Commun. 2007;12:1218-20. doi:10.1039/b618570c.

10. Clausell-Tormos J, Lieber D, Baret JC, El-Harrak A, Miller OJ, Frenz L, et al. Droplet-based microfluidic platforms for the encapsulation and screening of mammalian cells and multicellular organisms. Chem Biol. 2008;15(5):427-37. doi:10.1016/j.chembiol.2008.04.004.

11. Wang BL, Ghaderi A, Zhou H, Agresti J, Weitz DA, Fink GR, et al. Microfluidic high-throughput culturing of single cells for selection based on extracellular metabolite production or consumption. Nat Biotechnol. 2014;32(5):473-8. doi:10.1038/nbt.2857.

12. Mazutis L, Gilbert J, Ung WL, Weitz DA, Griffiths AD, Heyman JA. Singlecell analysis and sorting using droplet-based microfluidics. Nat Protoc. 2013;8(5):870-91. doi:10.1038/nprot.2013.046.

13. El Debs B, Utharala R, Balyasnikova IV, Griffiths AD, Merten CA. Functional single-cell hybridoma screening using droplet-based microfluidics. Proc Natl Acad Sci USA. 2012;109(29):11570-5. doi:10.1073/pnas.1204514109.

14. Sjostrom SL, Bai Y, Huang M, Liu Z, Nielsen J, Joensson HN, et al. Highthroughput screening for industrial enzyme production hosts by droplet microfluidics. Lab Chip. 2014;14(4):806-13. doi:10.1039/c3Ic51202a.

15. van Heerden JH, Wortel MT, Bruggeman FJ, Heijnen JJ, Bollen YJ, Planque $R$, et al. Lost in transition: start-up of glycolysis yields subpopulations 
of nongrowing cells. Science. 2014;343(6174):1245114. doi:10.1126/ science.1245114.

16. Abate AR, Hung T, Mary P, Agresti JJ, Weitz DA. High-throughput injection with microfluidics using picoinjectors. Proc Natl Acad Sci USA. 2010;107(45):19163-6. doi:10.1073/pnas.1006888107.

17. Baret JC, Miller OJ, Taly V, Ryckelynck M, El-Harrak A, Frenz L, et al. Fluorescence-activated droplet sorting (FADS): efficient microfluidic cell sorting based on enzymatic activity. Lab Chip. 2009;9(13):1850-8. doi:10.1039/ b902504a.

18. Angermayr SA, Hellingwerf KJ. On the use of metabolic control analysis in the optimization of cyanobacterial biosolar cell factories. J Phys Chem B. 2013;117(38):11169-75. doi:10.1021/jp4013152.

19. Angermayr $S A$, van der Woude $A D$, Correddu $D$, Vreugdenhil A, Verrone $V$, Hellingwerf KJ. Exploring metabolic engineering design principles for the photosynthetic production of lactic acid by Synechocystis sp. PCC6803. Biotechnol Biofuels. 2014;7:99. doi:10.1186/1754-6834-7-99.

20. Brouzes E, Medkova M, Savenelli N, Marran D, Twardowski M, Hutchison $\mathrm{JB}$, et al. Droplet microfluidic technology for single-cell high-throughput screening. Proc Natl Acad Sci USA. 2009;106(34):14195-200. doi:10.1073/ pnas.0903542106.

21. Abalde-Cela S, Gould A, Liu X, Kazamia E, Smith AG, Abell C. Highthroughput detection of ethanol-producing cyanobacteria in a microdroplet platform. J R Soc Interface. 2015; doi:10.1098/rsif.2015.0216.

22. Labarre J, Chauvat F, Thuriaux P. Insertional mutagenesis by random cloning of antibiotic resistance genes into the genome of the cyanobacterium Synechocystis strain PCC 6803. J Bacteriol. 1989;171(6):3449-57.
23. Griese M, Lange C, Soppa J. Ploidy in cyanobacteria. FEMS Microbiol Lett 2011;323(2):124-31. doi:10.1111/j.1574-6968.2011.02368.x.

24. Schneider D, Fuhrmann E, Scholz I, Hess WR, Graumann PL. Fluorescence staining of live cyanobacterial cells suggest non-stringent chromosome segregation and absence of a connection between cytoplasmic and thylakoid membranes. BMC Cell Biol. 2007;8:39. doi:10.1186/1471-2121-8-39.

25. Jain $I H$, Vijayan $V$, O'Shea EK. Spatial ordering of chromosomes enhances the fidelity of chromosome partitioning in cyanobacteria. Proc Natl Acad Sci USA. 2012;109(34):13638-43. doi:10.1073/pnas.1211144109.

26. Beck C, Hertel S, Rediger A, Lehmann R, Wiegard A, Kolsch A, et al. Daily expression pattern of protein-encoding genes and small noncoding RNAs in synechocystis sp. strain PCC 6803. Appl Environ Microbiol. 2014:80(17):5195-206. doi:10.1128/AEM.01086-14.

27. Agresti JJ, Antipov E, Abate AR, Ahn K, Rowat AC, Baret JC, et al. Ultrahigh-throughput screening in drop-based microfluidics for directed evolution. Proc Natl Acad Sci USA. 2010;107(9):4004-9. doi:10.1073/ pnas.0910781107.

28. Sjostrom SL, Joensson HN, Svahn HA. Multiplex analysis of enzyme kinetics and inhibition by droplet microfluidics using picoinjectors. Lab Chip. 2013;13(9):1754-61. doi:10.1039/c3lc41398e.

29. Tillich UM, Lehmann S, Schulze K, Duhring U, Frohme M. The optimal mutagen dosage to induce point-mutations in Synechocystis sp. PCC6803 and its application to promote temperature tolerance. PLoS One. 2012;7(11):e49467. doi:10.1371/journal.pone.0049467.

\section{Submit your next manuscript to BioMed Central and take full advantage of:}

- Convenient online submission

- Thorough peer review

- No space constraints or color figure charges

- Immediate publication on acceptance

- Inclusion in PubMed, CAS, Scopus and Google Scholar

- Research which is freely available for redistribution

Submit your manuscript at

www.biomedcentral.com/submit

C Biomed Central 